\title{
Evaluation of the genetic structure of indigenous Okinawa Agu pigs using microsatellite markers
}

\author{
Shihei Touma" ${ }^{1, *}$, Aisaku Arakawa², and Takuro Oikawa ${ }^{3}$
}

* Corresponding Authors: Shihei Touma Tel: +81-980-56-5142, Fax: +81-980-56-4803,

E-mail: toumashh@pref.okinawa.lg.jp

${ }^{1}$ Okinawa Prefectural Livestock and Grassland Research Center, Nakijin, Okinawa 905-0426, Japan

${ }^{2}$ Institute of Livestock and Grassland Science, National Agriculture and Food Research Organization (NARO),

Tsukuba, Ibaraki 305-0901, Japan

${ }^{3}$ Faculty of Agriculture, University of the Ryukyus,

Nishihara, Okinawa 903-0213, Japan

ORCID

Shihei Touma

https://orcid.org/0000-0002-0752-6609

Aisaku Arakawa

https://orcid.org/0000-0002-7438-8269

Takuro Oikawa

https://orcid.org/0000-0002-5001-270X

Submitted Jan 12, 2019; Revised Mar 17, 2019; Accepted May 7, 2019
Objective: Agu pigs are indigenous to the Okinawa prefecture, which is the southernmost region of Japan. Agu pigs were exposed to a genetic bottleneck during the 20th century, due to the introduction of European pig breeds. The objective of this study was to elucidate the genetic structure of Agu pigs and to determine their relationships with those of five European breeds, two Chinese breeds and Ryukyu wild boar using microsatellite markers.

Methods: A total of 203 DNA samples from 8 pig breeds were used in this study. Genotyping was performed using 21 microsatellite markers distributed across 17 chromosomes.

Results: Numbers of effective alleles in Agu pigs were fewer than in European breeds and Ryukyu wild boar. Among domestic pigs, Agu pigs had the lowest heterozygosity (0.423) and highest inbreeding coefficient $\left(\mathrm{F}_{\mathrm{IS}}=0.202\right)$, indicating a severe loss of heterozygosity in Agu pigs possibly due to inbreeding. Neighbor-joining tree analysis was performed based on Reynolds' genetic distances, which clustered Agu pigs with Duroc pigs. However, principal component analysis revealed a unique genetic position of the Agu pig, and the second principal component separated Agu pigs from all other breeds. Structure analysis with the optimal assumption of seven groups $(\mathrm{K}=7)$ indicated that Agu pigs form an independent cluster from the other breeds. In addition, high and significant $\mathrm{F}_{\mathrm{ST}}$ values $(0.235$ to 0.413$)$ were identified between Agu pigs and the other breeds.

Conclusion: This study revealed a substantial loss of genetic diversity among Agu pigs due to inbreeding. Our data also suggest that Agu pigs have a distinctive genetic structure, although gene flows from European breeds were observed.

Keywords: Agu Pig; Genetic Structure; Genetic Diversity; Indigenous Okinawa Pig; Microsatellite Marker

\section{INTRODUCTION}

Agu pigs are the only indigenous pig species in Japan that are raised in the Okinawa prefecture, southern Japan. Morphological appearances of Agu pigs are characterized by small sizes (approximately $100 \mathrm{~kg}$ at maturity), black coarse hair, semi-erect ears and sagging abdomens. Traditionally, Agu pigs were a typical source of food in Okinawa. But to improve their small body sizes and slow growth, Berkshire and Yorkshire pigs were introduced into Okinawa in 1904. Moreover, after World War II, more productive and economical European breeds were introduced and farmed. These included the breeds Landrace, Large White, and Duroc. As a consequence, Agu pigs faced imminent extinction, with dramatic decreases in the numbers of pure individuals from 104,321 animals in 1899 to 30 in 1980 [1,2]. In the 1980s, the local government collected 18 animals and started a conservation program with several enthusiasts.

It is generally believed that the ancestors of Agu pigs were introduced from the Asian continent, probably from China, in the latter half of the 14th century when the ancient King- 
dom of Okinawa began to trade with China [2]. In support of this assertion, phylogenetic analyses using mitochondrial DNA (mtDNA) control regions revealed that the haplotypes of Agu pigs were clustered into the Asian clade [3-5]. However, mtDNA provide only maternal genetic information and does not reflect the history of inheritance as shown by nuclear genomes, which carry male-mediated gene flows. Thus, genetic structures of Agu pigs currently remain unclear. Recently, pork from this breed has again become popular among consumers owing to its superior meat quality, with high intramuscular fat contents and high juiciness [6]. Agu pigs have also been recognized as a valuable genetic resource, and the desire to construct robust conservation schemes for Agu pigs necessitates an understanding of their genetic structure. Thus, we evaluated genetic diversity and phylogenetic relationships among Agu pigs, Chinese and European breeds and Ryukyu wild boar using 21 microsatellite markers.

\section{MATERIALS AND METHODS}

\section{Animals and DNA sample collection}

Tissue samples were collected according to the guidelines for proper conduct of animal experiments of the Science Council of Japan. Tissue samples from 34 Agu pigs were collected from 26 farms on Okinawa and Ishigaki islands. Because pedigree information is incomplete at many Agu pig farms, we collected samples based on interviews with farmers and using pedigree information to ensure that samples were as unrelated as possible. DNA samples from 31 Landrace, 30 Large White, 31 Duroc, 32 Berkshire, 11 Jinhua, and 14 Meishan pigs were collected from several farms in Japan. Twenty DNA samples were collected from Ryukyu wild boars (Sus scrofa riukiuanus) on Okinawa, Ishigaki and Iriomote islands. Samples from European breeds were collected from unrelated pigs. Jinhua and Meishan pig samples were collected from an inbred strain because the founding population was small. DNA was extracted using conventional phenol/chloroform techniques.

\section{Microsatellite genotyping}

Genotyping was performed using 21 microsatellite markers distributed across 17 chromosomes; these markers were selected based on informativeness and readability (Supplementary Table S1). Microsatellite fragments were amplified using polymerase chain reactions (PCR) with $42 \mathrm{ng}$ samples of pig genomic DNA and fluorophore-labelled primers. The PCR were performed in final volumes of $15 \mu \mathrm{L}$ containing $1.5 \mu \mathrm{L}$ of $10 \times$ PCR buffer, $0.9 \mu \mathrm{L}$ of $25 \mathrm{mM} \mathrm{MgCl}_{2}, 1.5 \mu \mathrm{L}$ of $8 \mathrm{mM}$ dNTP, 3 pmol of each primer and 0.4 units of Taq DNA polymerase (Applied Biosystems, Foster City, CA, USA). Thermal cycling was performed using a GeneAmp PCR System 9600 (Applied Biosystems, USA) with an initial denaturation for 9 min at $94^{\circ} \mathrm{C}$, followed by 40 cycles of $30 \mathrm{~s}$ at $94^{\circ} \mathrm{C}, 30 \mathrm{~s}$ at an- nealing temperature (Supplementary Table S1) and $30 \mathrm{~s}$ at $72^{\circ} \mathrm{C}$ and then a final extension step at $72^{\circ} \mathrm{C}$ for $5 \mathrm{~min}$. To genotype samples, PCR products were electrophoresed using an ABI 3130xl DNA sequencer (Applied Biosystems, USA). Allele sizes were then determined using Gene-Mapper software (Version 3.7, Applied Biosystems, USA).

\section{Data analyses}

Numbers of alleles $\left(\mathrm{N}_{\mathrm{A}}\right)$, effective numbers of alleles $\left(\mathrm{N}_{\mathrm{E}}\right)$, observed heterozygosity $\left(\mathrm{H}_{\mathrm{O}}\right)$, and expected heterozygosity $\left(\mathrm{H}_{\mathrm{E}}\right)$ were calculated using GenAlEx version 6.5 software [7]. Pairwise $\mathrm{F}_{\mathrm{ST}}$ and inbreeding coefficients $\left(\mathrm{F}_{\mathrm{IS}}\right)$ were calculated using FSTAT version 2.9.3 [8]. Pairwise comparisons of $\mathrm{F}_{\mathrm{ST}}$ values were performed using Bonferroni corrections. Deviations from the Hardy-Weinberg equilibrium (HWE) were calculated using GENEPOP program [9]. Polymorphic information contents (PIC) were calculated and allele diversities at each locus were determined using CERVUS version3.0 [10]. Reynolds' genetic distances [11] were calculated and a phylogenetic tree was constructed via Neighbor-joining tree analysis (NJ) clustering using Populations version 1.2.32 software [12]. Robustness of tree topology was tested using the bootstrap method with 1,000 repetitions. The genetic distances between individuals were determined as $-\ln$ (proportions of shared alleles) using a microsatellite analyzer [13] and were used to construct a NJ tree of 203 individuals from 8 pig breeds using MEGA 7.0 [14]. Principal component analysis (PCA) of gene frequencies were performed using the PCAGEN program [15] and Bayesian clustering was performed using STRUCTURE version 2.3.4 [16] to infer population structures and degrees of admixture. Numbers of assumed clusters $(\mathrm{K})$ were estimated by performing 10 independent runs for each $\mathrm{K}$ value from 1 to 10 with a burn-in period of 100,000 iterations followed by 100,000 Markov Chain Monte Carlo iterations. The optimal $\mathrm{K}$ value was estimated according to the Evanno $\Delta \mathrm{K}$ method using STRUCTURE HARVESTER 0.6.94 application [17]. The results of STRUCTURE analysis were averaged using CLUMPAK 1.1 [18].

\section{RESULTS}

Polymorphisms of 21 microsatellite loci in 8 breeds are shown in Supplementary Table S2. In accordance with FAO guidelines $\left(\mathrm{N}_{\mathrm{A}}>4\right.$ per locus) for population diversity analyses (http:// www.fao.org/3/a-aq569e.pdf, Secondary Guidelines MoDAD), $\mathrm{N}_{\mathrm{A}}$ ranged from 8 (SW72, SW813) to 23 (SW1119). Moreover, all markers apart from SW1437 had PIC of greater than 0.5, indicating that they are highly informative [19].

Genetic diversities of Agu pigs, five European and two Chinese pig breeds and Ryukyu wild boar are shown in Table 1. $\mathrm{N}_{\mathrm{A}}$ ranged from 2.91 in Jinhua pigs to 6.38 in Landrace pigs. $\mathrm{N}_{\mathrm{E}}$ were lower in Agu pigs than in European breeds and 
Table 1. Genetic diversity parameters in eight breeds

\begin{tabular}{lccccccc}
\hline Breed & $\mathbf{N}$ & $\mathbf{N}_{\mathrm{A}}$ & $\mathrm{N}_{\mathrm{E}}$ & $\mathbf{H}_{0}$ & $\mathbf{H}_{\mathrm{E}}$ & $\mathbf{F}_{\mathrm{IS}}$ & DHWE \\
\hline Agu & 34 & 5.10 & 2.31 & 0.423 & 0.531 & 0.202 & 10 \\
Landrace & 31 & 6.38 & 3.41 & 0.608 & 0.672 & 0.096 & 4 \\
Large White & 30 & 5.24 & 2.87 & 0.578 & 0.621 & 0.069 & 2 \\
Duroc & 31 & 4.57 & 2.73 & 0.568 & 0.598 & 0.050 & 1 \\
Berkshire & 32 & 5.05 & 2.92 & 0.561 & 0.618 & 0.093 & 2 \\
Jinhua & 11 & 2.91 & 2.17 & 0.566 & 0.530 & -0.067 & 0.111 \\
Meishan & 14 & 3.29 & 2.29 & 0.466 & 0.524 & 0.668 & 0.481 \\
Ryukyu wild boar & 20 & 6.10 & 3.40 & 0.347 & 0.67 & 17 \\
\hline
\end{tabular}

$\mathrm{N}_{A}$, Numbers of alleles; $\mathrm{N}_{\mathrm{E},}$ effective numbers of alleles; $\mathrm{H}_{0}$, observed heterozygosity; $\mathrm{H}_{\mathrm{E},}$ expected heterozygosity; $\mathrm{F}_{\mathrm{I}, \mathrm{i}}$ inbreeding coefficients; DHWE, numbers of loci deviating from Hardy-Weinberg equilibrium (DHWE) at $p<0.05$ among eight breeds.

Table 2. Reynolds' genetic distance (below diagonal) and pairwise $F_{S T}$ estimates (above diagonal)

\begin{tabular}{lcccccccc}
\hline Items & A & L & W & D & B & J & M & R \\
\hline Agu (A) & - & $0.235^{* * *}$ & $0.244^{* * *}$ & $0.256^{* * *}$ & $0.256^{* * *}$ & $0.390^{* * *}$ & $0.413^{* * *}$ & $0.336^{* * *}$ \\
Landrace (L) & 0.251 & - & $0.108^{* * *}$ & $0.165^{* * *}$ & $0.147^{* * *}$ & $0.311^{* * *}$ & $0.329^{* * *}$ & $0.274^{* * *}$ \\
Large White (W) & 0.256 & 0.102 & - & $0.227^{* * *}$ & $0.179^{* * *}$ & $0.331^{* * *}$ & $0.342^{* * *}$ & $0.291^{* * *}$ \\
Duroc (D) & 0.280 & 0.177 & 0.240 & - & $0.230^{* * *}$ & $0.354^{* * *}$ & $0.363^{* * *}$ & $0.319^{* * *}$ \\
Berkshire (B) & 0.274 & 0.160 & 0.192 & 0.251 & - & $0.359^{* * *}$ & $0.371^{* * *}$ & $0.308^{* * *}$ \\
Jinhua (J) & 0.478 & 0.361 & 0.372 & 0.415 & 0.434 & - & $0.325^{* * *}$ & $0.318^{* * *}$ \\
Meishan (M) & 0.525 & 0.397 & 0.408 & 0.442 & 0.455 & 0.369 & - & $0.327^{* * *}$ \\
Ryukyu wild boar (R) & 0.407 & 0.321 & 0.332 & 0.385 & 0.371 & 0.378 & 0.392 & - \\
\hline
\end{tabular}

*** $p<0.001$.

Ryukyu wild boar. With the exception of Ryukyu wild boar, Agu pigs had the lowest $\mathrm{H}_{\mathrm{O}}(0.423)$ and the highest of $\mathrm{F}_{\mathrm{IS}}$ (0.202) values. Numbers of loci that deviated from the HWE in each breed ranged from 1 (Duroc and Jinhua) to 17 (Ryukyu wild boar), whereas 10 loci showed significant deviations from the HWE in Agu pigs $(\mathrm{p}<0.05)$.

To evaluate genetic differentiation between Agu pigs and other breeds, we calculated Reynolds' genetic distances and $\mathrm{F}_{\mathrm{ST}}$ values (Table 2). The breed with the closest genetic distance to Agu pigs was the Landrace pig (0.251), and the farthest genetic relationship was with Meishan pigs (0.525). Genetic distances between Agu pigs and European pig breeds were shorter (0.251 to 0.280 ) than those between Agu pigs and Asian breeds (Jinhua, Meishan, and Ryukyu wild boar; 0.407 to 0.525$)$. Moreover, genetic distances were shorter between European pig breeds ( 0.102 to 0.251 ) than between Asian breeds ( 0.369 to 0.392$)$. Pairwise $\mathrm{F}_{\mathrm{ST}}$ values between Agu pigs and the other breeds $(0.235$ to 0.413$)$ were significant $(\mathrm{p}<0.001)$, falling into the range of great to very great genetic differentiation [20].

In Figure 1, we present a NJ tree that was constructed using Reynolds' genetic distances to evaluate phylogenetic relationships between Agu pigs and the other breeds. The eight breeds were divided into three clades and the Agu pig was clustered with Duroc pigs. Landrace and Large White and Berkshire pigs formed the second clade, and the Asian breeds formed the remaining clade.

We constructed a NJ tree of 203 individuals based on $\ln$ (proportions of shared alleles) distances and determined whether Agu individuals can be distinguished from individuals of other breeds (Figure 2). In these analyses, all individuals were classified into their breed clusters, and 34 Agu individuals formed a single clade without mixing with other breeds.

In PCA based on allele frequencies of the 21 microsatellite markers (Figure 3), the first (PC1) and second (PC2) principal components represented $26.4 \%$ and $19.6 \%$ of the total variation, respectively. This analysis divided the eight breeds into three clusters as follows: cluster I (Asian), Meishan, Jinhua, and Ryukyu wild boar; cluster II (European), Landrace, Large White, Duroc, and Berkshire and cluster III, Agu. In particular, PC1 separated Asian and European breeds and PC2 separated Agu pigs from other breeds.

Figure 4 shows the results of population structure analysis using STRUCTURE software. Asian and European clusters were generated at $\mathrm{K}=2$ and Agu pigs were included in both clusters. At $\mathrm{K}=5$, Agu pigs were clearly separated from the other breeds. Calculations using the Evanno method gave an optimal K value of 7 (Supplementary Figure S1), and population structure analysis at this level generated distinct clusters for all breeds but the Chinese breeds. Finally, Ryukyu wild boar was subdivided into two populations in analysis with $\mathrm{K}=8$. 


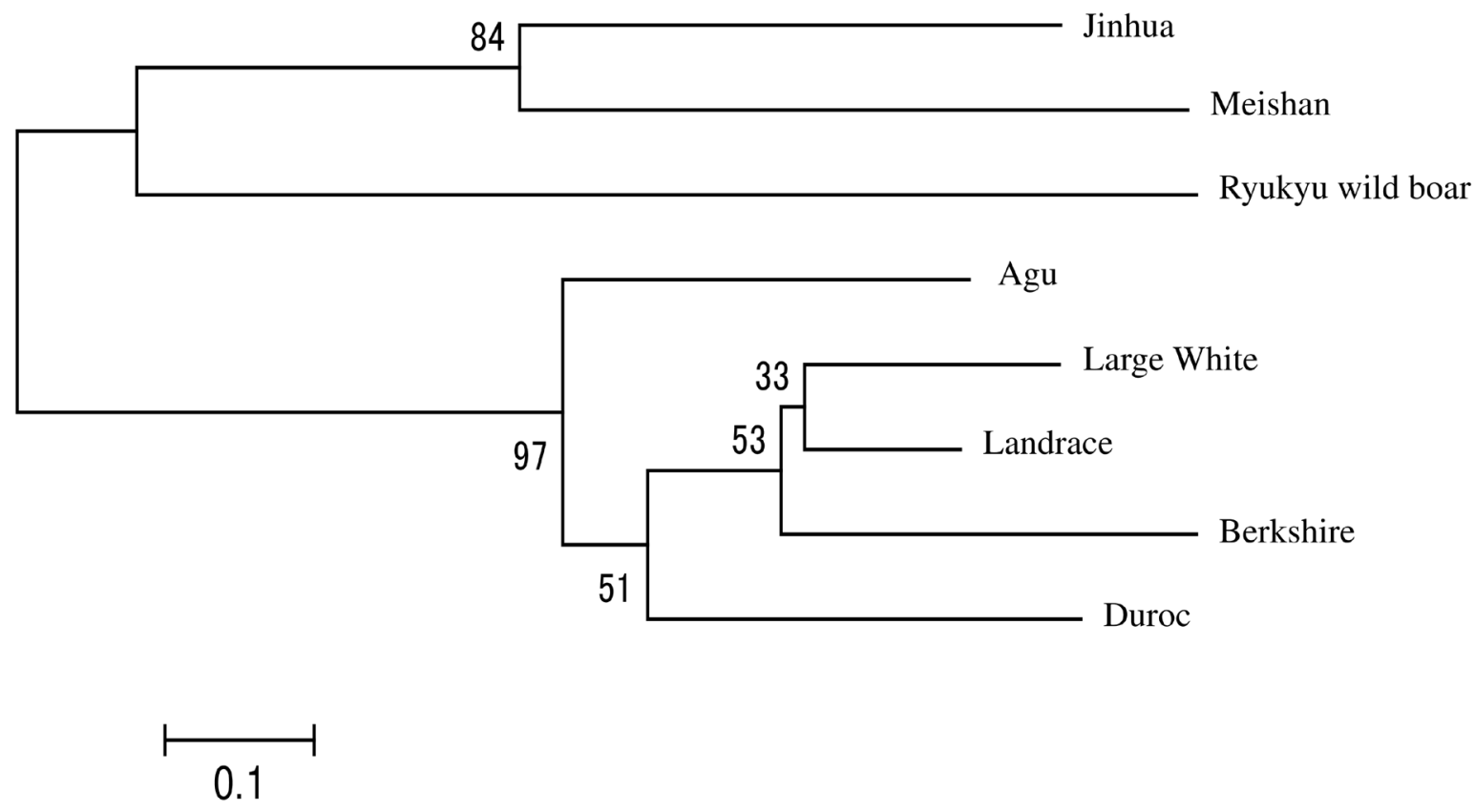

Figure 1. Neighbor-joining tree based on Reynolds' genetic distance from eight breeds. The numbers at the nodes are bootstrap support values in 1,000 replicates.

\section{DISCUSSION}

\section{Genetic diversity within Agu pigs}

In this study, genetic structures of Agu pigs were investigated using analyses of 21 microsatellite markers in 203 animals from 8 pig breeds. Parameters of genetic diversity among European breeds were within previously reported ranges (Table 1) [21-23], although among Chinese breeds, the $\mathrm{H}_{\mathrm{O}}$ value of Meishan pigs was lower than that shown in previous

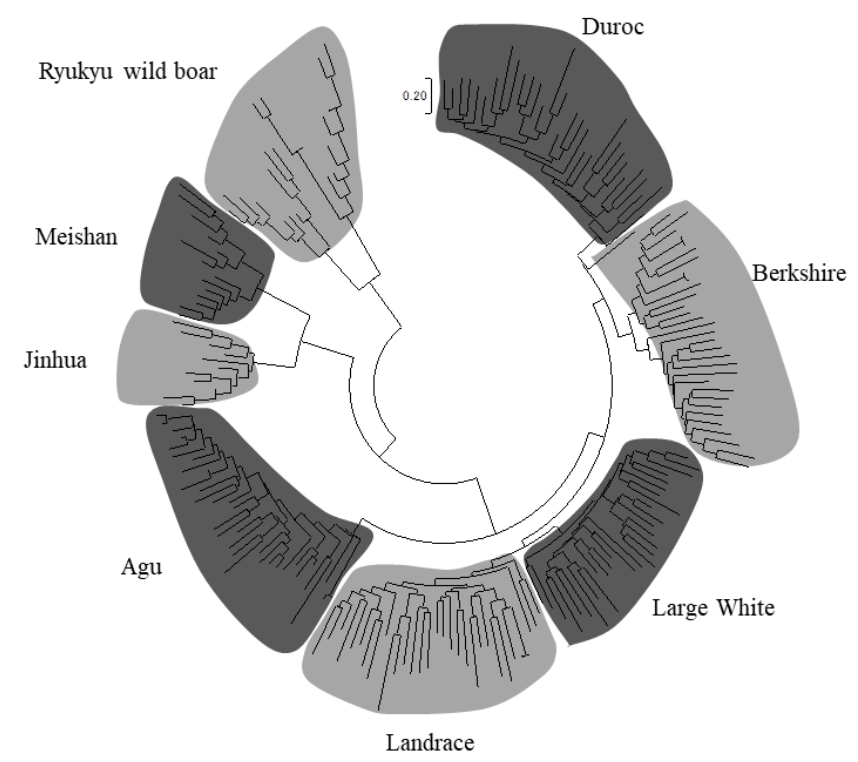

Figure 2. The neighbor-joining tree constructed based on -In (proportion of share allele) distance among 203 individuals from eight breeds. studies $[23,24]$. $\mathrm{N}_{\mathrm{A}}$ and $\mathrm{N}_{\mathrm{E}}$ values in Jinhua pigs were lower than in previous studies $[25,26]$, whereas the corresponding $\mathrm{H}_{\mathrm{O}}$ value was higher. Agu pigs had lower $\mathrm{N}_{\mathrm{E}}$ than European breeds and Ryukyu wild boar. Among domestic breeds, Agu pigs had the lowest $\mathrm{H}_{\mathrm{O}}$ value and the highest $\mathrm{F}_{\mathrm{IS}}$ value, and 10 of 21 markers deviated significantly from the HWE in Agu pigs. These results indicate severe loss of heterozygosity in Agu pig populations, likely resulting from inbreeding. Hence, following replacement with European breeds, low numbers of Agu individuals in a small population likely favored inbreeding. Consequently, Agu pigs had small litter sizes (total number born, 4.8) [27] and low conception rates (20\%) [28]. In contrast with Agu pigs, Meishan and Jinhua pigs had low $\mathrm{F}_{\text {IS }}$ values, likely reflecting breeding strategies that avoid mating between close relatives.

\section{Genetic influences from European pig breeds in Agu pigs}

It is assumed that Japanese Agu pigs originated from the first introduction of pigs from the Asian continent. A previous study of mtDNA control regions by Touma et al [5] revealed that most Agu individuals have East Asian haplotypes, whereas only $14 \%$ of Agu pigs carried European haplotypes. These data are evidence of gene flows from European breeds into Agu pig populations. In our studies of nuclear DNA, phylogenetic tree analysis and assessments of Reynolds' genetic distances revealed shorter genetic distances between Agu pigs and European breeds than between Agu and Chinese breeds (Table 2; Figure 1). Moreover, genetic structure analysis (Figure 4) with $\mathrm{K}=2$ showed that Agu pigs are a genetic admixture of Euro- 


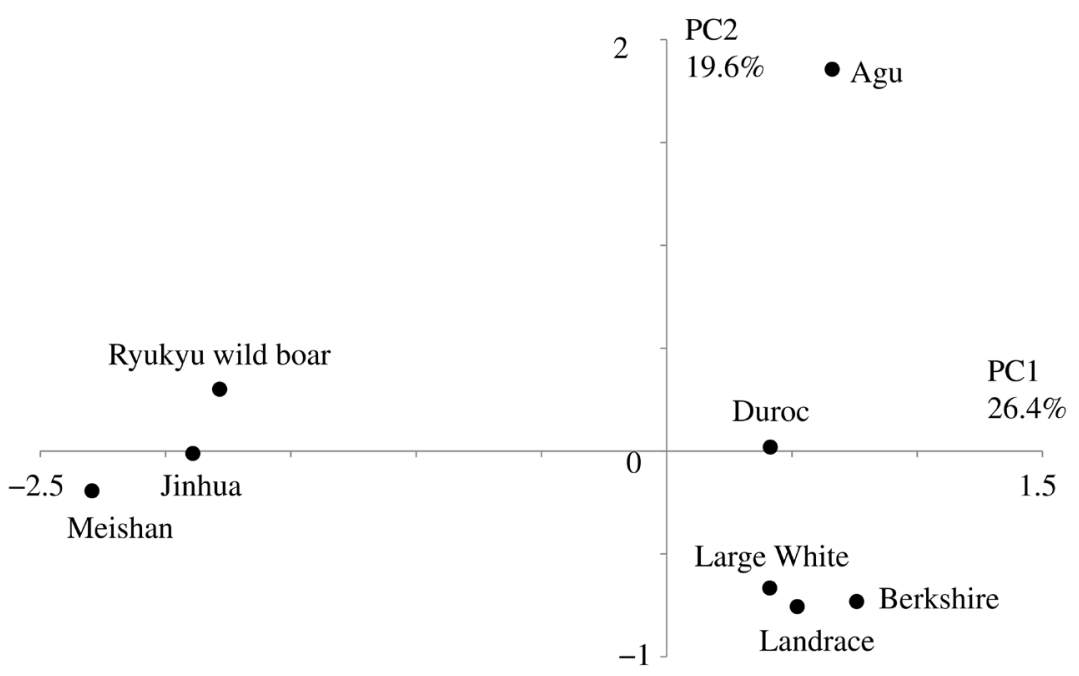

Figure 3. Result of the principal component analysis based on allele frequency of 21 microsatellites. The first and second principal components accounted for $26.4 \%$ and $19.6 \%$ of the total variance, respectively.
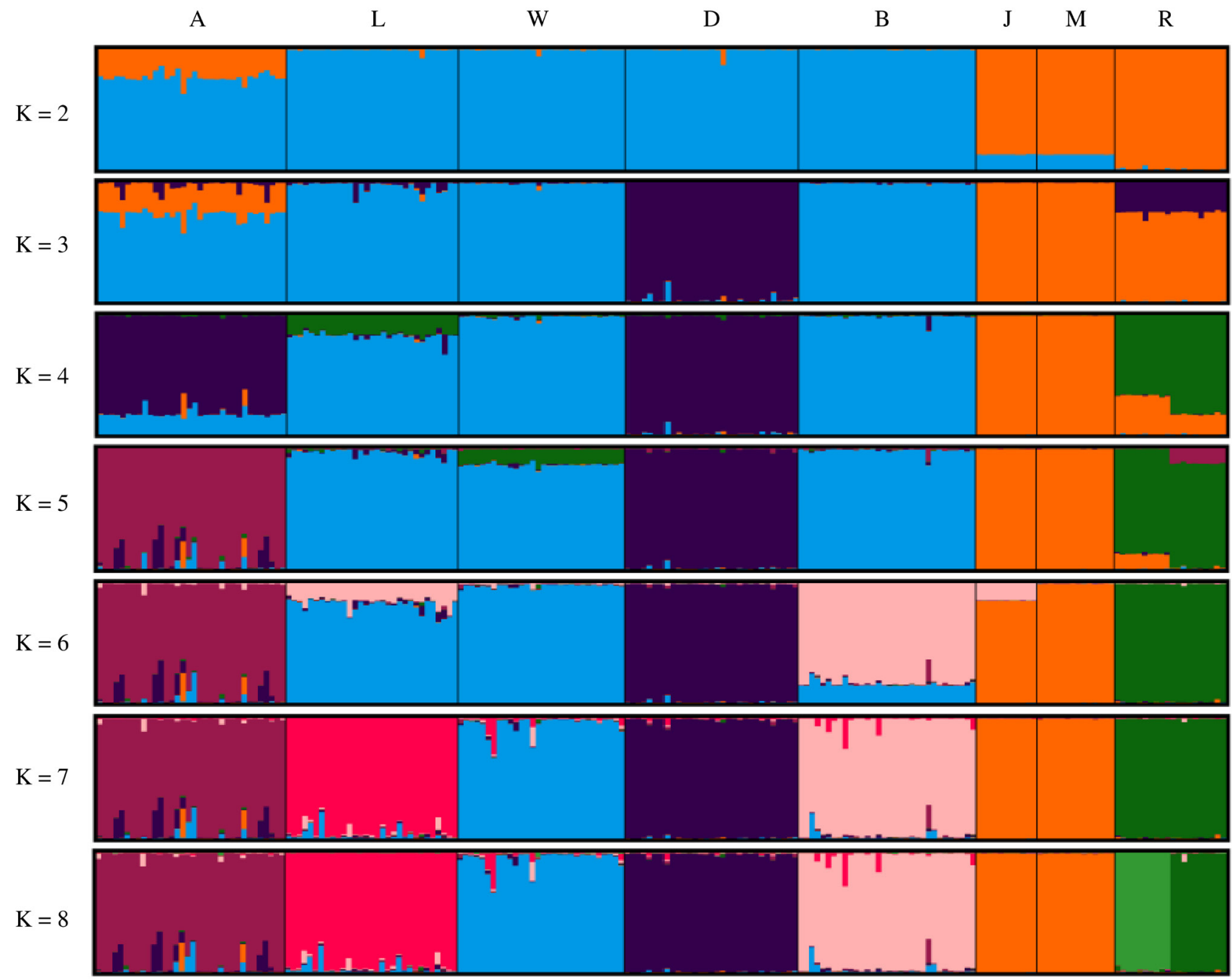

Figure 4. Population structures of eight breeds. Single vertical bars correspond to individual animals, and K indicates the number of assumed clusters. A, Agu; L, Landrace; W, Large white; D, Duroc; B, Berkshire; J, Jinhua; M, Meishan; R, Rykyu wild boar. 
pean and Asian clusters, with predominance of the European cluster. Thus, whereas the nuclear genomes of Agu pigs were influenced by European breeds, Asian mtDNA haplotypes remain predominant. These results suggest that the European breeds that were introduced into Okinawa after 1904 were often used as sires for breeding with Agu females.

Formation of the current genetic structure of Agu pigs Taken with a previous study of mtDNA [5], our analyses of nuclear DNA suggest that Agu pig populations have maternal Asian origins, but that strong nuclear genetic influences were imposed from European breeds after 1904. Nonetheless, PCA analysis showed that Agu pigs are genetically unique among European and Asian breeds (Figure 3). Our optimal structure analysis at $\mathrm{K}=7$, as determined using the Evanno $\Delta \mathrm{K}$ method, also showed that Agu pigs form an independent cluster from the other breeds (Figure 4). In agreement, population differentiation values $\left(\mathrm{F}_{\mathrm{ST}}\right)$ differed greatly between Agu pigs and European and Asian breeds ( $\mathrm{p}<0.001$; Table 2), confirming that Agu pigs are genetically distinct. Perhaps the bottleneck effect contributed to this distinctive genetic structure by promoting genetic drift. In addition, Agu pigs were isolated from other pig breeds by the conservation program from the 1980 's, likely enhancing genetic differences. In our $\mathrm{NJ}$ tree, which was based on proportions of shared allele distances, 34 Agu individuals were assigned to a single group that was not mixed with other breeds (Figure 2). These data suggest little gene flow between Agu pigs and other breeds in recent decades. However, we have not eliminated the possibility that other breeds contributed to the genetic structure of Agu pigs.

Ryukyu wild boar (Sus scrofa riukiuanus) has inhabited the Okinawa islands since the Pleistocene period [29]. In a previous study of mtDNA control regions, no Ryukyu wild boar haplotypes were found in an Agu pig population [5]. Our nuclear DNA analyses also revealed genetic distinctions between Ryukyu wild boar and Agu pigs (Table 2; Figures 1-4), suggesting little genetic influence from Ryukyu wild boar.

Structure analysis at $\mathrm{K}=8$ subdivided Ryukyu wild boar into two subpopulations (Figure 4), and one of these included individuals from Okinawa Island, whereas the other subpopulation was from Ishigaki and Iriomote islands. Because these subpopulations are separated by sea, the resulting geographic impossibility of gene flows likely contributed to differentiation. Moreover, Ryukyu wild boar had the highest $\mathrm{F}_{\mathrm{IS}}$ value (0.481) in this study (Table 1 ), and this may be a consequence of the Wahlund effect [30], which is caused by sampling from subpopulations. The low genetic diversity of this small island population may also have contributed to this high $\mathrm{F}_{\text {IS }}$ value [24].

\section{CONCLUSION}

We analyzed nuclear DNA using microsatellite markers and revealed a substantial loss of genetic diversity among Agu pigs due to inbreeding. Our data also demonstrated the unique genetic position of Agu pigs, albeit with nuclear gene flow from European breeds. The present findings regarding the genetic structure and diversity of this indigenous pig population will be useful to improve the conservation program for Agu pigs. Currently, high-density single nucleotide polymorphism (SNP) panels, such as the Illumina Porcine SNP 60K BeadChip, permit a more comprehensive genome-wide investigation of genetic structure and genetic diversity than microsatellite markers. To confirm our results, further investigations are needed using SNP arrays.

\section{CONFLICT OF INTEREST}

We certify that there is no conflict of interest with any financial organization regarding the material discussed in the manuscript.

\section{ACKNOWLEDGMENTS}

This study was supported by the Program for the Promotion of Agu pork from Okinawa prefecture, Japan. We thank Dr. Okumura of Japan Association for Techno-innovation in Agriculture, Forestry and Fisheries (JATAFF) for providing European and Chinese pig breeds and Ryukyu wild boar DNA samples.

\section{REFERENCES}

1. Editorial Committee of the History of Nago City. The history of Nago city book of materials. 1. Statistical material of early modern times. Okinawa, Japan: Nago City Public Office; 1980. p. 294-5.

2. Miyagi Y. Okinawa zairaibuta Agu no fukugen to Okinawa no shokubunnka (The restoration of Okinawa indigenous pig Agu and food culture of Okinawa). The Livestock Industry Magazine 1998;407:46-50.

3. Okumura N, Kurosawa Y, Kobayashi E, et al. Genetic relationship amongst the major non-coding regions of mitochondrial DNAs in wild boars and several breeds of domesticated pigs. Anim Genet 2001;32:139-47. https://doi.org/10.1046/j.13652052.2001.00757.x

4. Li KY, Li KT, Cheng CC, Chen CH, Hung CY, Ju YT. A genetic analysis of Taoyuan pig and its phylogenetic relationship to Eurasian pig breeds. Asian-Australas J Anim Sci 2015;28:45766. https://doi.org/10.5713/ajas.14.0595

5. Touma S, Shimabukuro H, Arakawa A, Oikawa T. Maternal lineage of Okinawa indigenous Agu pig inferred from mitochondrial DNA control region. Asian-Australas J Anim Sci 2019;32:501-7. https://doi.org/10.5713/ajas.18.0378

6. Touma S, Onaga M, Toubaru N, Oikawa T. Breed charac- 
teristics of indigenous pigs in Okinawa: Growth performance, carcass traits and meat quality. Jpn J Swine Sci 2017;54:1219. https://doi.org/10.5938/youton.54.3_121

7. Peakall R, Smouse PE. GenAlEx 6: genetic analysis in Excel. Population genetic software for teaching and research. Mol Ecol Notes 2006;6:288-95.

8. FSTAT. A program to estimate and test gene diversities and fixation indices (version 2.9.3) [Internet]. Goudet J.; c2005 [cited 2018 Sep 11]. Available from http://www2.unil.ch/ popgen/softwares/fstat.htm

9. Raymond M, Rousset F. GENEPOP (version 1.2): Population genetics software for exact tests and ecumenicism. J Hered 1995;86:248-9. https://doi.org/10.1093/oxfordjournals.jhered. a111573

10. Marshall TC, Slate J, Kruuk LE, Pemberton JM. Statistical confidence for likelihood-based paternity inference in natural populations. Mol Ecol 1998;7:639-55. https://doi.org/10.1046/ j.1365-294x.1998.00374.x

11. Reynolds J, Weir BS, Cockerham CC. Estimation of the coancestry coefficient: basis for a short-term genetic distance. Genetics 1983;105:767-79.

12. Langella O. Populations 1.2.32: a population genetic software; c1999 [cited $2019 \mathrm{Feb} 10$ ]. Available from http://bioinformatics. org/ tryphon/populations/

13. Dieringer D. Schlötterer D. Microsatellite analyzer (MSA): A platform independent analysis tool for large microsatellite data sets. Mol Ecol Notes 2003;3:167-9. https://doi.org/10.1046/j. 1471-8286.2003.00351.x

14. Kumar S, Stecher G, Tamura K. MEGA7: Molecular Evolutionary Genetics Analysis version 7.0 for bigger datasets. Mol Biol Evol 2016;33:1870-4. https://doi.org/10.1093/molbev/ msw054

15. PCAGEN. A program to perform a principal component analysis (PCA) on genetic data [Internet]. Goudet J.; c2005 [cited 2018 Sep 11]. Available from: http://www2.uni.ch/popgen/ pcagen.htm

16. Pritchard JK, Stephans M, Donnelly P. Inference of population structure using multilocus genotype data. Genetics 2000;155: 945-59.

17. Evanno G, Regnaut S, Goudet J. Detecting the number of clusters of individuals using the software STRUCTURE: a simulation study. Mol Ecol 2005;14:2611-20. https://doi.org/10.1111/ j.1365-294X.2005.02553.x

18. Kopelman NM, Mayzel J, Jakobsson M, Rosenberg NA, Mayrose I. CLUMPAK: a program for identifying clustering modes and packaging population structure inferences across $\mathrm{K}$. Mol Ecol Resour 2015;15:1179-91. https://doi.org/10.1111/1755-
0998.12387

19. Botstein D, White RL, Skolnick M, Davis RW. Construction of a genetic linkage map in man using restriction fragment length polymorphisms. Am J Hum Genet 1980;32:314-31.

20. Hartl DL, Clark AG. Principles of population genetics. 3rd ed. Sunderland, Sinauer Associates Inc; 1997. p. 118-9.

21. Kim TH, Kim KS, Choi BH, et al. Genetic structure of pig breeds from Korea and China using microsatellite loci analysis. J Anim Sci 2005;83:2255-63. https://doi.org/10.2527/2005. 83102255x

22. Vicente AA, Carolino MI, Sousa MC, et al. Genetic diversity in native and commercial breeds of pigs in Portugal assessed by microsatellites. J Anim Sci 2008;86:2496-507. https://doi. org/10.2527/jas.2007-0691

23. Luetkemeier ES, Sodhi M, Schook LB, Malhi RS. Multiple Asian pig origins revealed through genomic analyses. Mol Phylogenet Evol 2010;54:680-6. https://doi.org/10.1016/j. ympev.2009.11.004

24. Murakami K, Yoshikawa S, Konishi S, Ueno Y, Watanabe S, Mizoguchi Y. Evaluation of genetic introgression from domesticated pigs into the Ryukyu wild boar population on Iriomote Island in Japan. Anim Genet 2014;45:517-23. https://doi.org/ 10.1111/age. 12157

25. Li SJ, Yang SL, Zhao SH, et al. Genetic diversity analyses of 10 indigenous Chinese pig populations based on 20 microsatellites. J Anim Sci 2004;82:368-74. https://doi.org/10.2527/ 2004.822368x

26. Wang X, Cao HH, Geng SM, Li HB. Genetic diversity of 10 Indigenous Pig breeds in China by Using microsatellite markers. Asian-Australas J Anim Sci 2004;17:1219-22. https://doi. org/10.5713/ajas.2004.1219

27. Touma S, Oikawa T. Breed characteristics of indigenous Okinawa Agu pigs analyzed by body measurements and reproductive traits. Nihon Chikusan Gakkaiho 2017;88:103-13. https://doi.org/10.2508/chikusan.88.103

28. Yamauchi S, Nakamura S, Yoshimoto T, Nakada T, Ashizawa $\mathrm{K}$, Tatemoto H. Prediction of the estrous cycle and optimal insemination time by monitoring vaginal electrical resistance (VER) in order to improve the reproductive efficiency of the Okinawan native Agu pig. Anim Reprod Sci 2009;113:311-6. https://doi.org/10.1016/j.anireprosci.2008.08.005

29. Oshiro I, Nohara T. Distribution of Pleistocene terrestrial vertebrates and their migration to the Ryukyus. Tropics 2000;10: 41-50. https://doi.org/10.3759/tropics.10.41

30. Wahlund S. Composition of population and correlation phenomenon from the point of view of inheritance theory. Hereditas 1928;11:65-106. 